\title{
In pictures - The British Dental Association Conference and Exhibition 2009
}

Please send any ideas for feature articles for
consideration to:
Rowena Milan,
British Dental Journal,
The Macmillan Building,
4-6 Crinan Street,
London
N19XW
Email: r.milan@nature.com

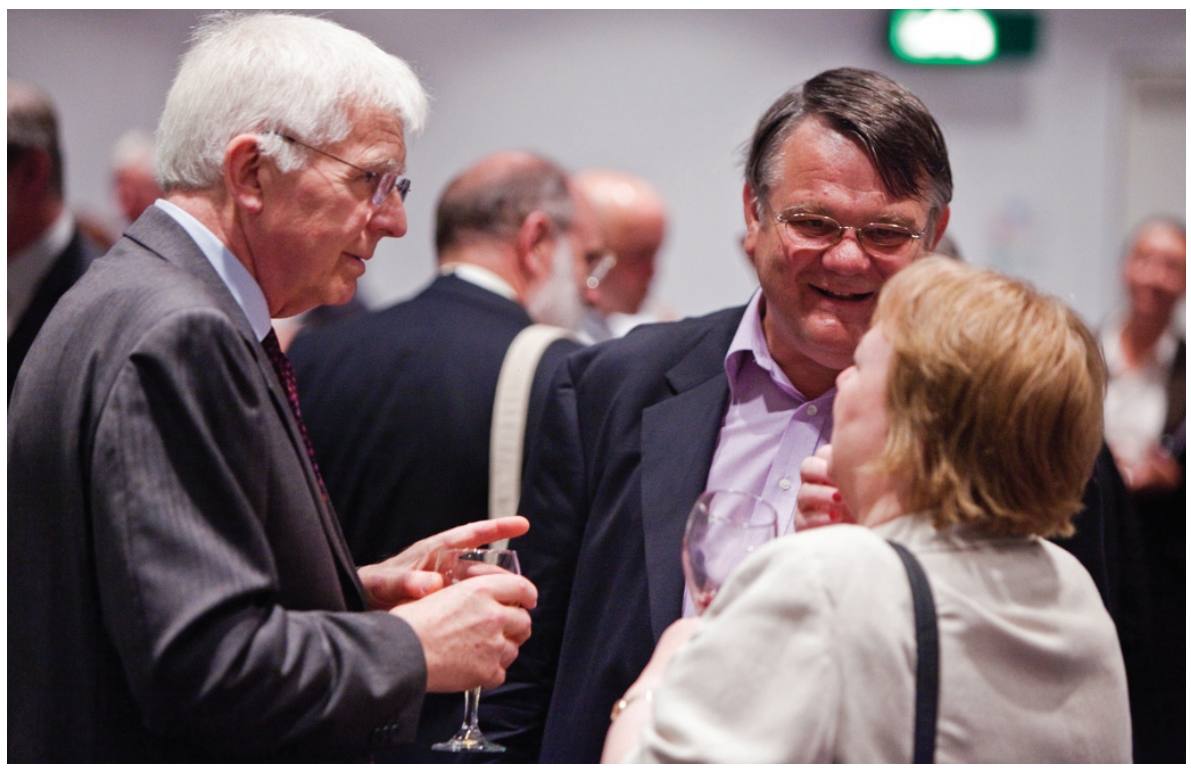

BDTA Executive Director Tony Reed, BDA Immediate Past President Gordon Watkins and BDA Executive Board Chair Susie Sanderson at the Corporate Sponsors' Reception

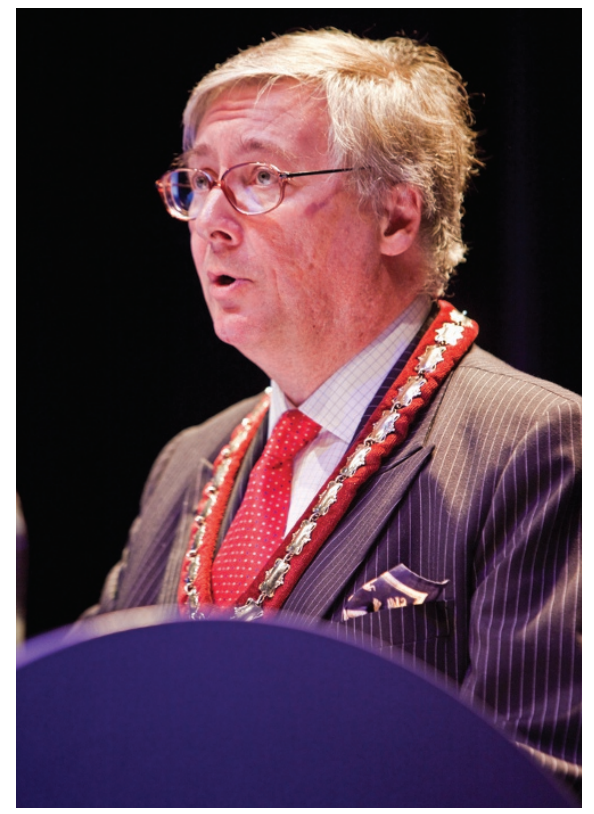

New BDA President Dr John Drummond

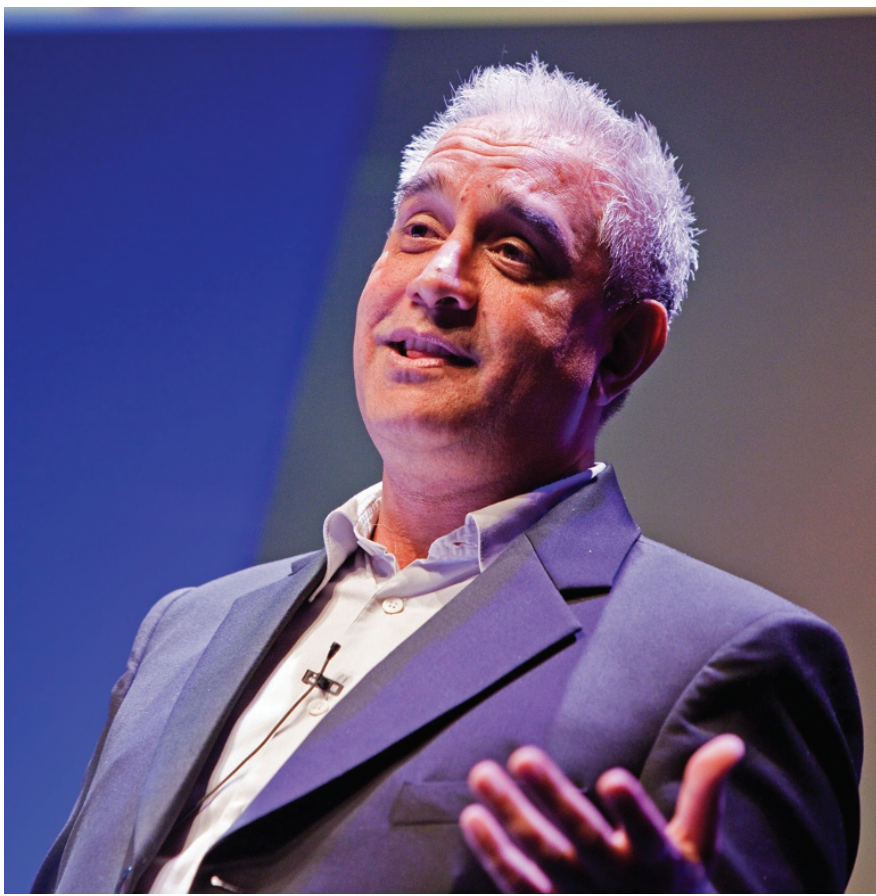

Charan Gill MBE, keynote speaker

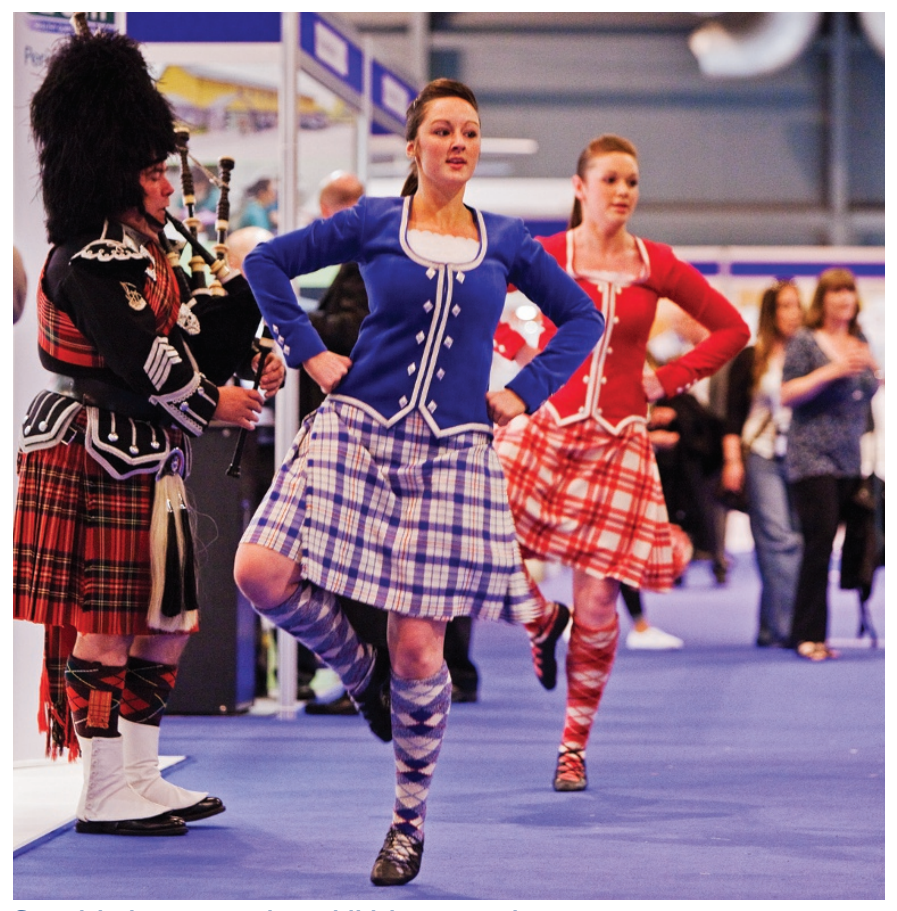

Scottish dancers at the exhibition reception 

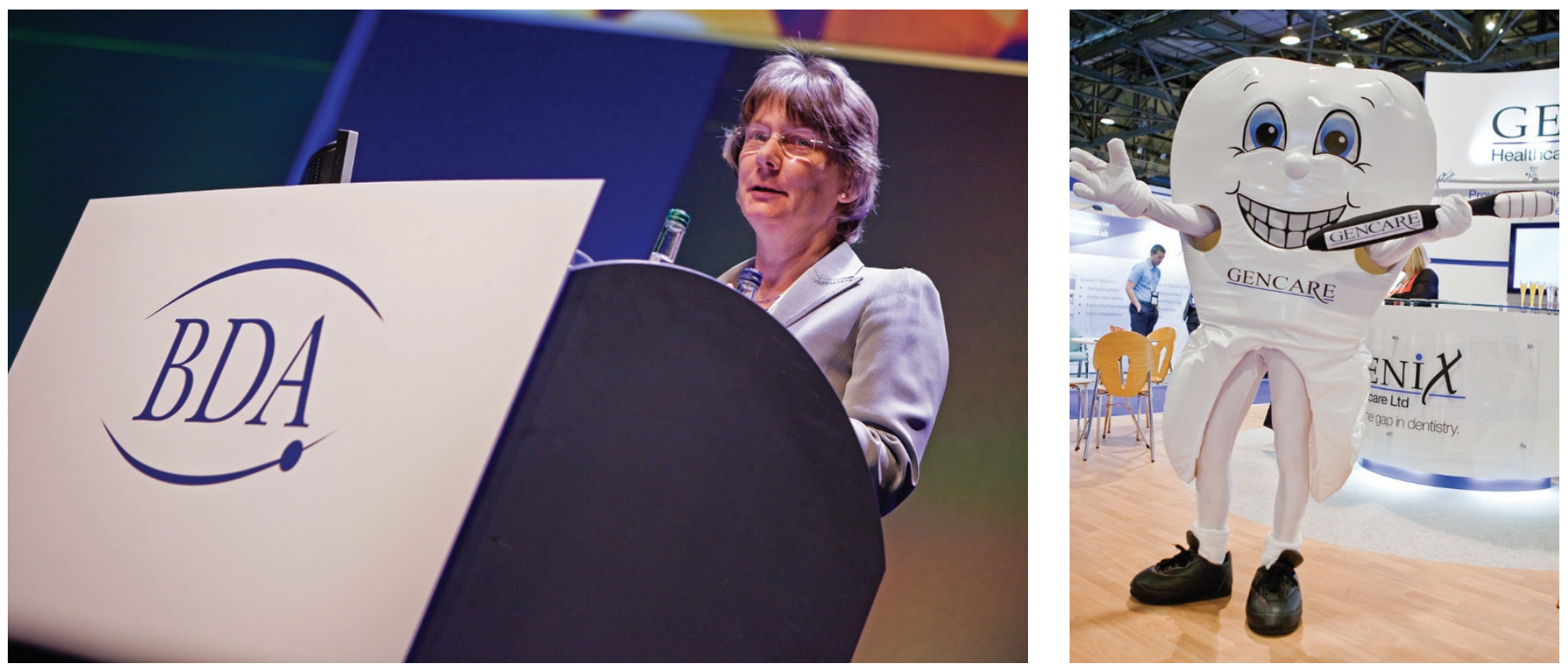

Margie Taylor, Chief Dental Officer, Scotland

A merry molar

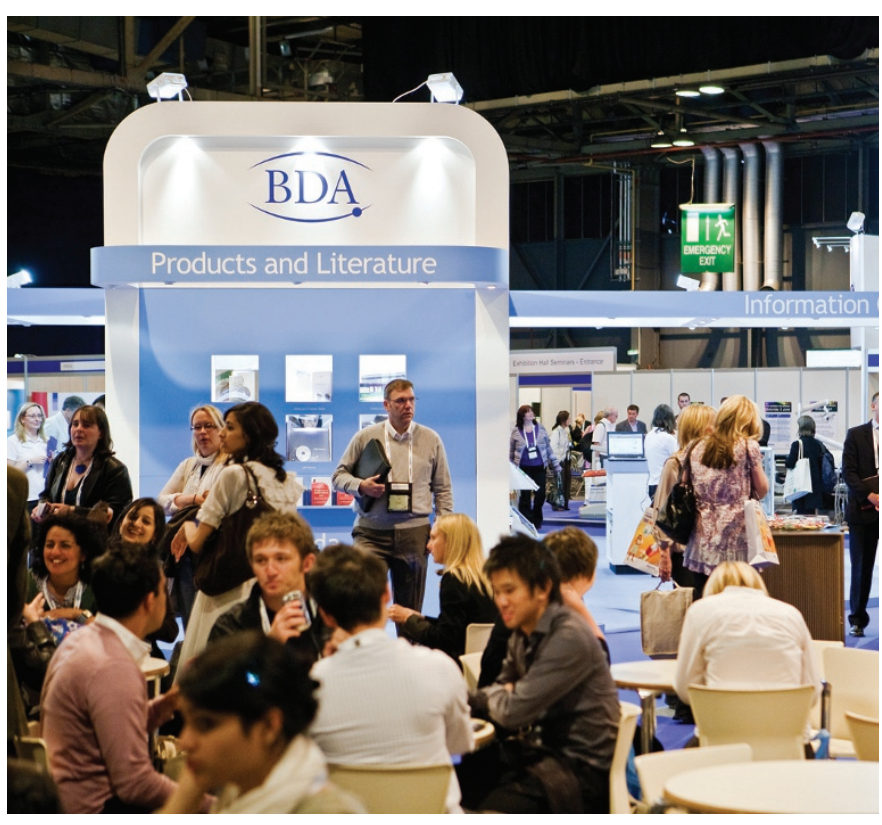

The BDA stand was well attended

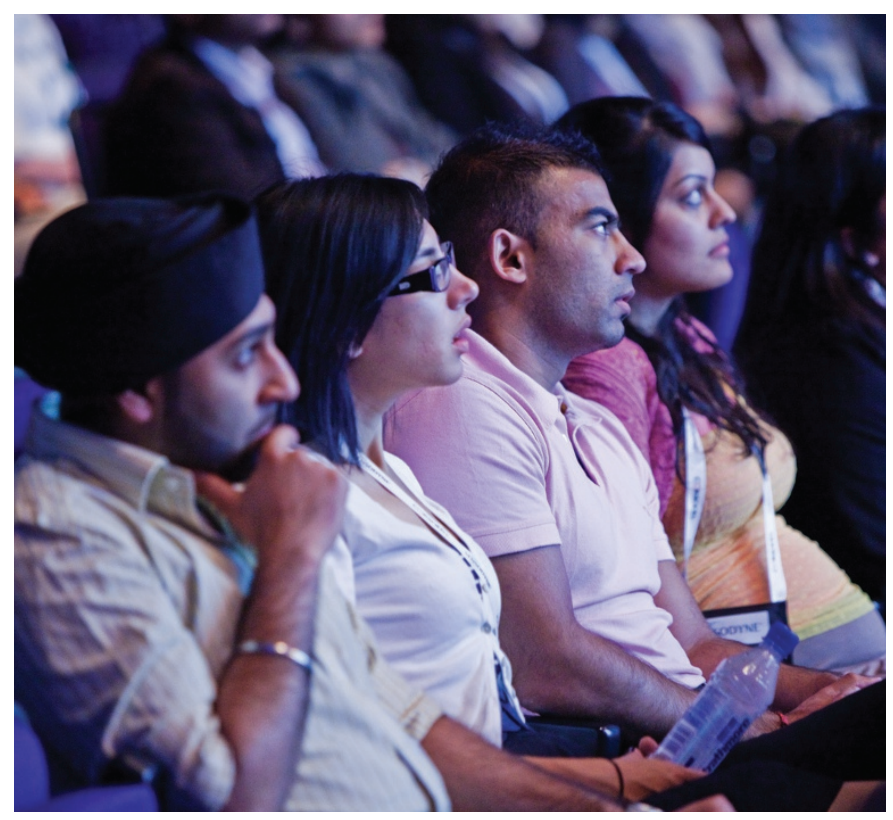

Rapt attention in one of the packed sessions

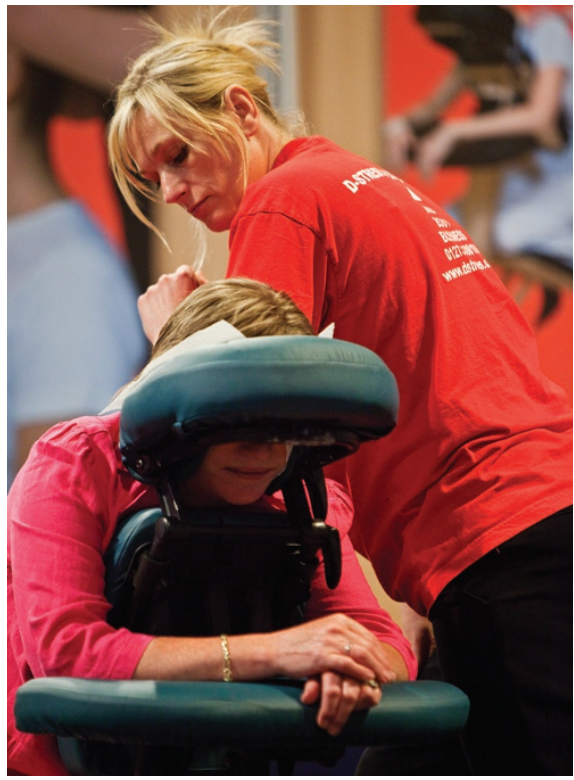

Massage to replenish the energy levels

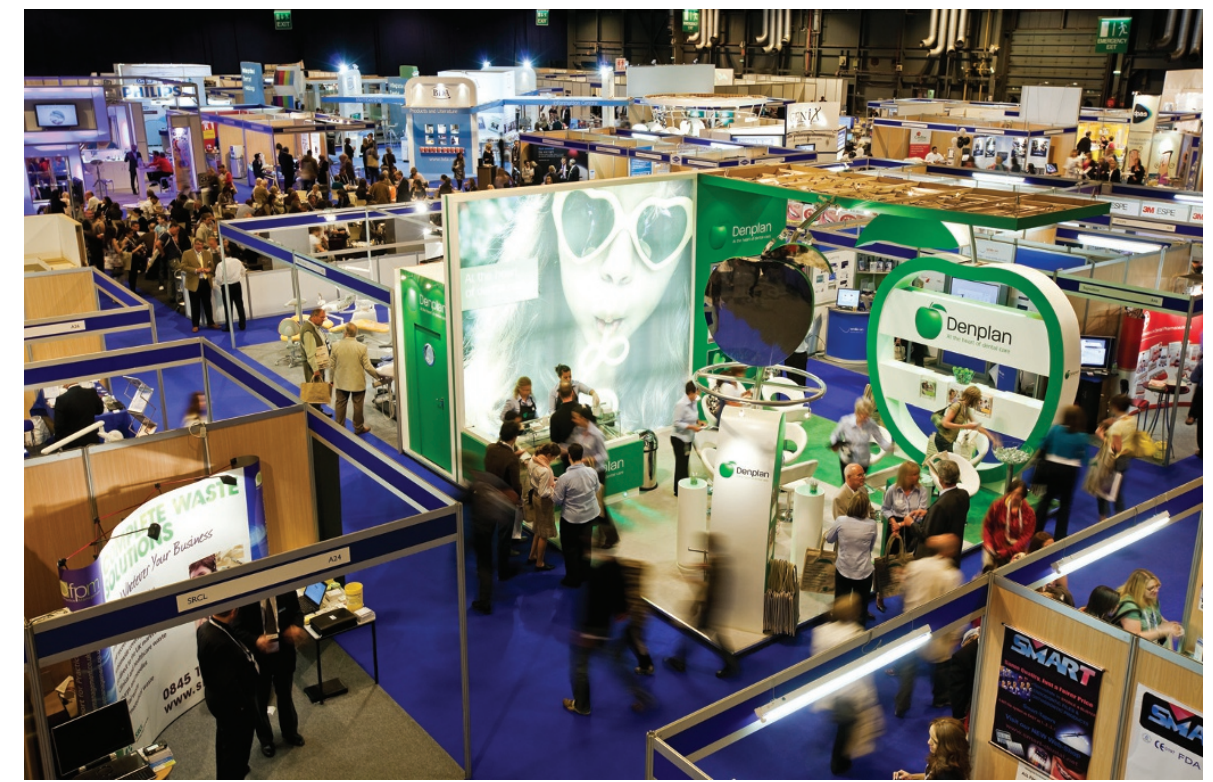

Delegates made the most of the busy exhibition 


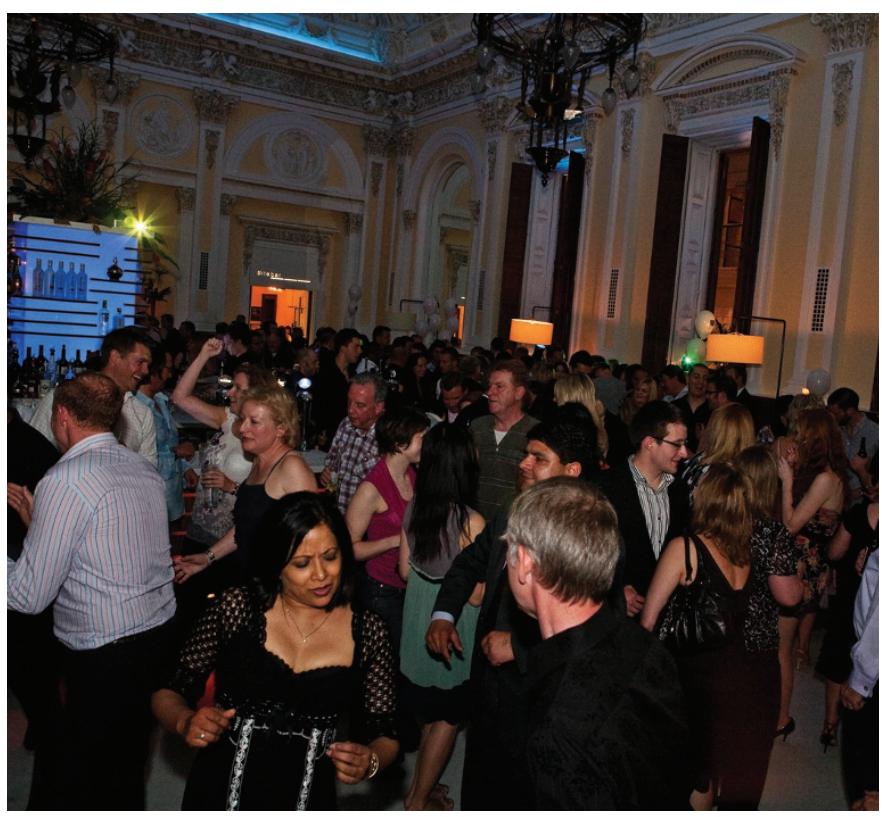

Guests at the Friday night party

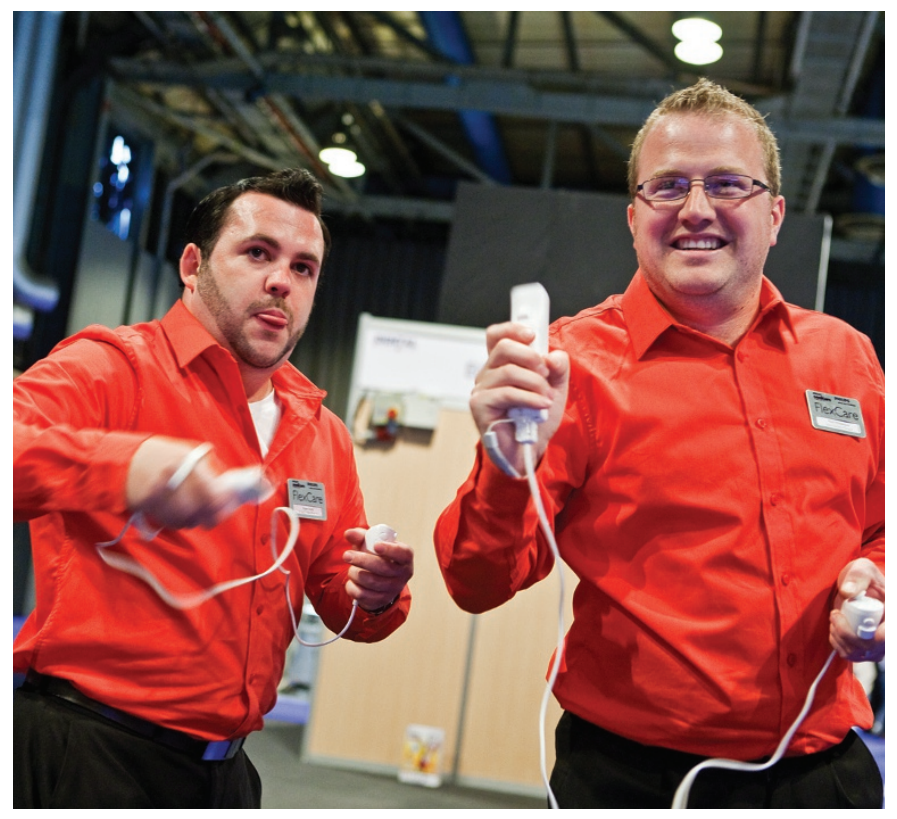

Who said conference was just work?

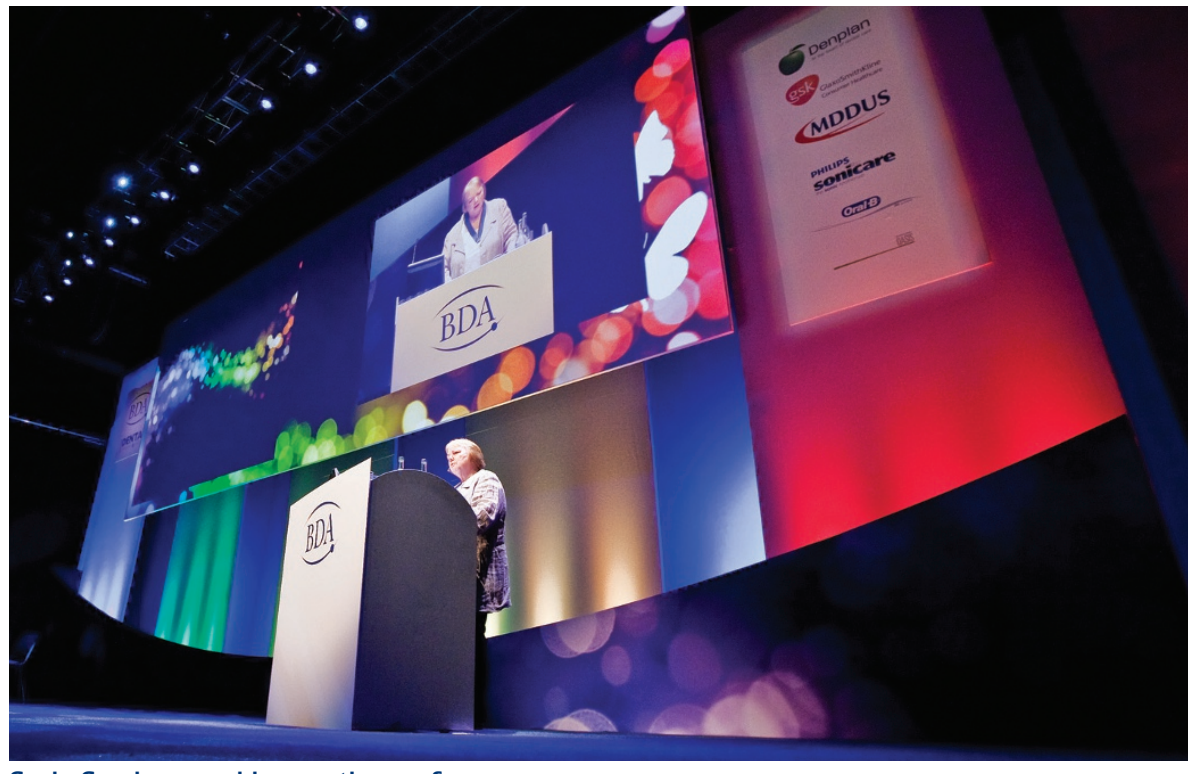

Susie Sanderson addresses the conference

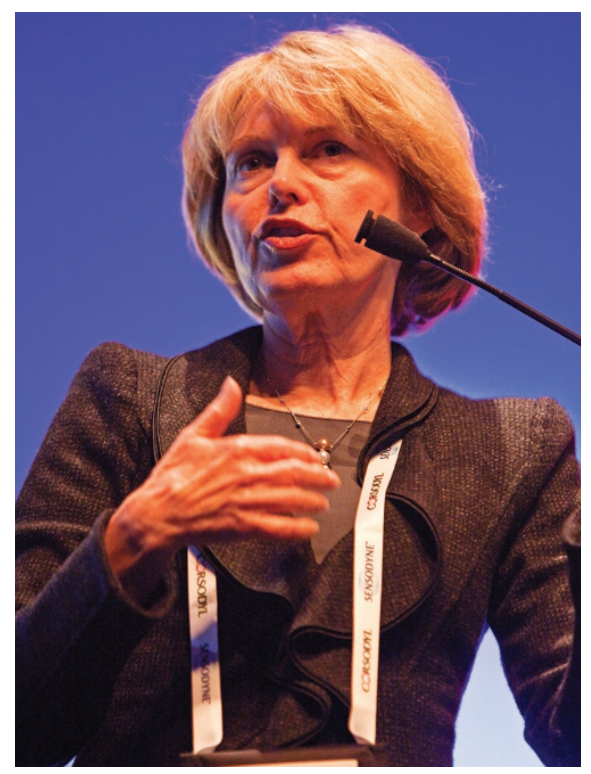

Main session speaker Cherilyn Sheets

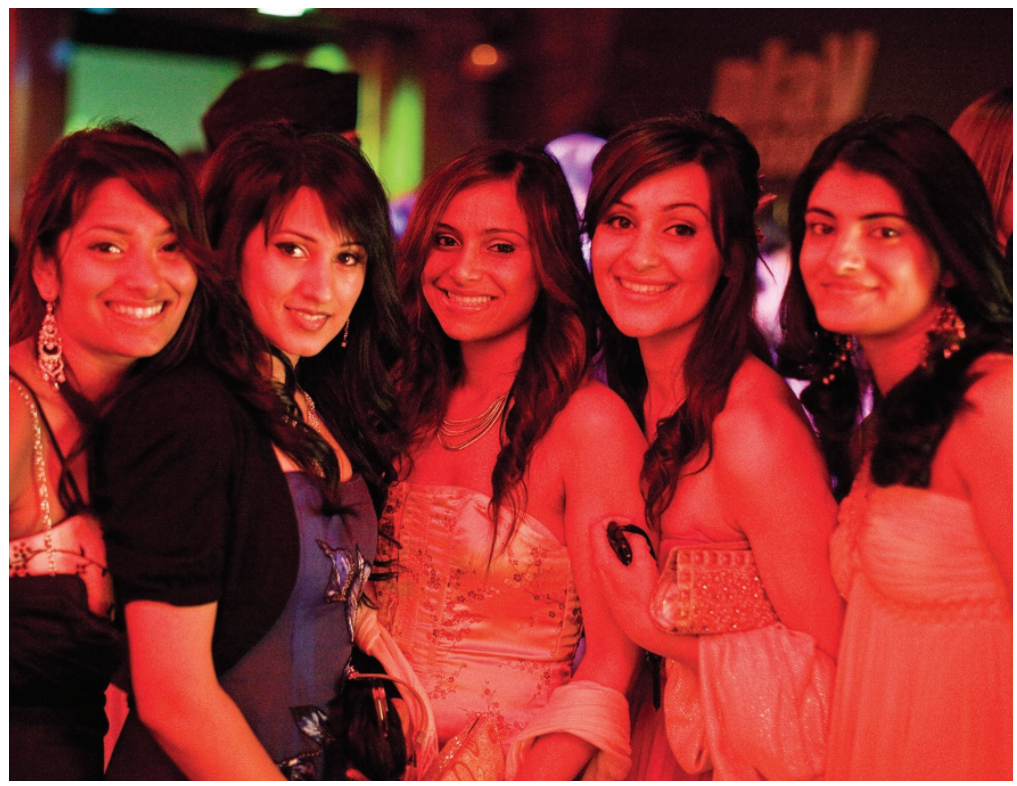

VDPs enjoying the annual VDP Ball

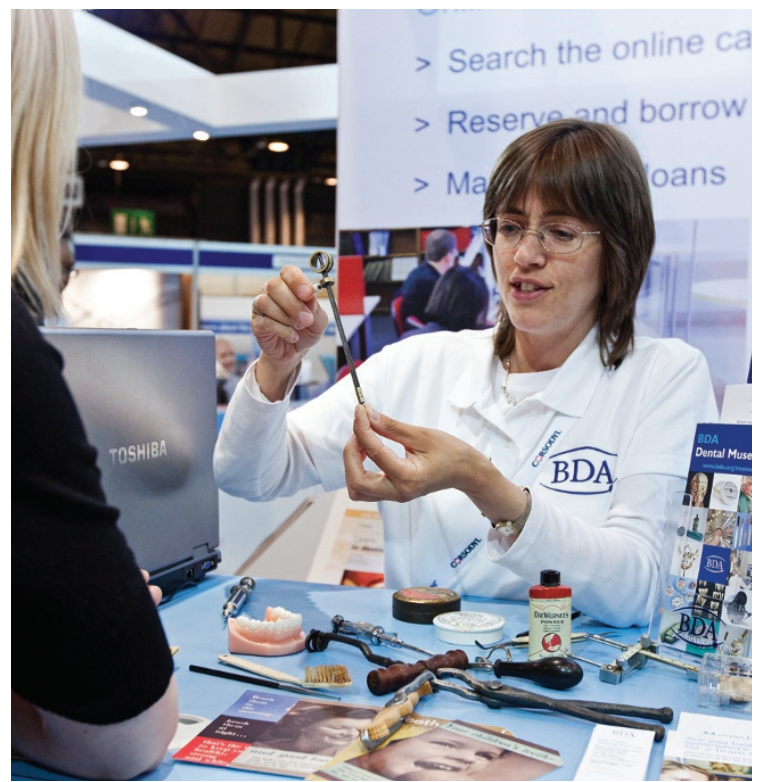

The BDA Museum was a popular stop 